\title{
Smart Polymeric Nanofibers for Topical Delivery of Levothyroxine
}

\author{
Anahita Fathi Azarbayjani ${ }^{1}$, Jayarama Reddy Venugopal ${ }^{2}$, Seeram Ramakrishna ${ }^{2}$, Perry Fung Chye Lim ${ }^{1}$, Yew Weng Chan ${ }^{3}$, \\ Sui Yung Chan ${ }^{1 *}$ \\ ${ }^{1}$ Department of Pharmacy, National University of Singapore, 18, Science Drive 4, 117543, Singapore \\ ${ }^{2}$ Division of Bioengineering, National University of Singapore, 2 Engineering Drive 3, 119260, Singapore \\ ${ }^{3}$ Department of Anaesthesiology, Singapore General Hospital, 169608, Singapore
}

Received, January 1, 2010; Revised, September 2, 2010; Accepted, September 22, 2010; Published, September 24, 2010

\begin{abstract}
Topical administration of levothyroxine $\left(\mathrm{T}_{4}\right)$ helps to reduces deposits of adipose tissue on skin. The question is whether topical application of $\mathrm{T}_{4}$ could lead to systemic effects. In the present study a series of nanofibrous membranes were electrospun into blends of poly vinyl alcohol (PVA) and poly-Nisopropylacrylamide (PNIPAM) to develop a sustained topical delivery of $\mathrm{T}_{4}$. The polymeric nanofiber mats were characterized by field emission scanning electron microscopy (FESEM) and fourier transform infrared (FTIR) spectroscopy. In vitro permeation of the drug from the polymeric nanofibers was studied using excised human skin and the permeation mechanism investigated using confocal microscopy. It was observed that polymeric nanofibers were able to sustain the penetration of $\mathrm{T}_{4}$ to the skin and help maintain the effective drug concentration in the skin layers for prolonged period. These formulations may have potential uses in topical products and can help to increase the accumulation of the active compound on the skin surface thus minimize the adverse side effects which may be caused by systemic absorption. This may result in consumer compliance, avoid frequent dosing and enhance the therapeutic effectiveness.
\end{abstract}

\section{INTRODUCTION}

Electrospinning technique is a novel method for generating polymeric nanoscale fibers. The nanosized fibers with high surface area-to-volume ratios and porosities are ideal for development of biosensors and biochips, drug delivery systems, wound healing and scaffold for tissue engineering (1-3). Biodegradable polymeric nanofibers are effective carriers for drug delivery and offer advantages such as reduced toxicity and increased therapeutic level and biocompatibility (4-6). Poly vinyl alcohol (PVA) is a hydrophilic polymer with distinct properties such as high degree of swelling, inherent non-toxicity and good biocompatibility (7). Nanofibers of PVA alone or blended with other polymers such as chitosan and gelatin have been studied (4, 5, 7-10). Blends of polymers have been widely used to enhance physical properties and physiological functionality of fiber mats $(5,10,11)$.

Poly (N-isopropylacrylamide) (PNIPAM) is a thermally reversible hydrogel with a lower critical solution temperature (LCST) of around $32^{\circ} \mathrm{C}$ in water. The cross-linked gel of this material swells and shrinks at temperatures below and above the LCST respectively, therefore a PNIPAM delivery system can provide sustained therapeutic levels of a drug by responding to the physiological signals of the body $(12,13)$. PNIPAM nanoparticles, hydrogels and liposomes coated with PNIPAM have been extensively studied as controlled drug delivery systems (14-21). The potential toxicity of this polymer has been tested subcutaneously and results did not show any toxic effects (22).

Levothyroxine $[3,5,3$ ', 5'-tetraiodothyronine $\left(\mathrm{T}_{4}\right)$ ] is a synthetic hormone administered orally for the treatment of hypothyroidism and goiter $(23,24)$. $\mathrm{T}_{4}$ stimulates lipid metabolism and induces lipolysis. Topical administration was reported to reduce deposits of adipose tissue in the skin (25-27). Presence of high concentration of $T_{4}$ in cosmetic creams raise questions if topical applications of these creams would lead to systemic absorption effects. Using radioactive marker, radioactivity was found in the plasma after skin application of $\mathrm{T}_{4}(28)$. However recent in vivo studies using liposomal formulations were not able to detect any systemic effect (26).

Correspondence Author: Sui Yung Chan, Department of Pharmacy, National University of Singapore, Singapore Email: phacsy@nus.edu.sg 
Topical application of dimethyl- $\beta$-cyclodextrin (DM $\beta$-CD) retained $\mathrm{T}_{4}$ on the skin without significant transdermal permeation (29). The aim of this work was to develop electrospun nanofiber mats of PVA, PNIPAM and PVA- PNIPAM complex as topical carriers for $\mathrm{T}_{4}$. We intend to show that polymeric nanofibers can sustain the penetration of $\mathrm{T}_{4}$ to the skin and help maintain the effective drug concentration in the skin layers for prolonged period while avoiding systemic absorption. The interactive effects of the two polymers on the resultant fiber were studied using FTIR and electron microscopy. Skin permeation of $\mathrm{T}_{4}$ from these nanofibers was investigated using excised human skin.

\section{MATERIALS AND METHODS}

\section{Materials}

Poly vinylalcohol (Mw 70000-100000 and >98\% hydrolyzed), poly (N-isopropylacrylamide) (Mw 20000-25000), levothyroxine, fluorescein and 4', 6diamidino-2-phenylindole (DAPI) were purchased from Sigma (Singapore). All other reagents were of analytical grade.

\section{HPLC Analysis}

T4 concentration was quantified by HPLC from Agilent HP (USA). The analysis was carried out using an X-bridge column $(3.5 \mu \mathrm{m}, 4.6 \mathrm{~mm} \times 100$ $\mathrm{mm}$; USA). Mobile phase was a 70:30 volume ratio of acetonitrile and $0.05 \mathrm{M}$ phosphate buffer adjusted to $\mathrm{pH} 3$ using phosphoric acid, flowing at a rate of $0.6 \mathrm{ml} / \mathrm{min}$. UV detection at wavelength 220 $\mathrm{nm}$ and injection volume $100 \mu \mathrm{L}$ gave a retention time of 9 min. Standard solutions of T4 (0.05 - 20 $\mu \mathrm{g} / \mathrm{ml})$ in $40 \% \mathrm{v} / \mathrm{v}$ ethanol were prepared. Coefficients of variation of intra- and inter-day measurements were $<5 \%$.

\section{Electrospinning of PVA/PNIPAM Nanofibers}

Polymeric solutions were obtained by dissolving the drug and polymer in water (for PVA and PVAPNIPAM) or in ethanol (for PNIPAM). Details of each formulation used in the electrospinning process are shown in Table 1. Fluorescein loaded PNIPAM solutions were developed for confocal imaging and studying the depth of the penetration of molecule from these fibers to the lower layers of the skin.

\begin{tabular}{|c|c|c|c|}
\hline \multirow[t]{2}{*}{ Formulation } & \multicolumn{2}{|c|}{$\begin{array}{c}\text { Polymer Concentration } \\
(\% \mathrm{w} / \mathrm{v})\end{array}$} & \multirow[t]{2}{*}{ Solvent } \\
\hline & PVA & PNIPAM & \\
\hline A & 10 & - & Water \\
\hline B & - & 10 & Ethanol \\
\hline $\mathrm{C}$ & - & 10 & Water \\
\hline $\mathrm{D}$ & 10 & 5 & Water \\
\hline $\mathrm{E}$ & 10 & 10 & Water \\
\hline
\end{tabular}

Nanofibers were fabricated using the electrospining method. The electrostatic spinner used for the experiments was equipped with an adjustable DC power supply (RP50-1.25 R/230 DDPM, Gamma high voltage Research, USA), a syringe pump (KD-100, KD scientific, Inc., USA) on which a 3-ml syringe was connected to a blunt $27 \mathrm{G}$ stainless steel needle. The applied voltage was set at $25 \mathrm{kV}$. The distance between the syringe and the fiber collector was kept constant at $13 \mathrm{~cm}$ for all experiments. A constant flow rate of $2 \mathrm{ml} / \mathrm{h}$ was applied to all the formulations. The depositions were performed at room temperature. The non-woven electrostatically spun fabric was removed from the collector and was dried under vacuum for a week at room temperature to remove residual solvent prior to usage.

\section{Fourier Transform Infrared Measurements (FTIR)}

Interaction between polymers and their functional groups in the nanofiber structures were studied using FTIR. Spectra of the fibers were taken with a Perkin Elmer (Spectrum 100; USA) in the wavelength region $500-4000 \mathrm{~cm}^{-1}$ at ambient temperature. Fiber mats were placed on a $\mathrm{KBr}$ holder in an enclosed sample chamber for FTIR spectroscopic study.

\section{Field Emission Scanning Electron Microscopy (FESEM)}

The surface topography of the electrospun fibers was assessed using a FESEM (Jeol JSM-6701F; Japan). Electrospun fibers were placed at the center of an aluminum stud using carbon tape. A very thin layer of platinum was applied to the fibers by a sputtering unit (Jeol JFC-1600 auto fine coater; Japan). Coated fibers were placed in the microscope chamber at high vacuum. Surface 
morphological features were obtained under $5 \mathrm{kV}$ accelerating voltage. The diameter distribution of the electrospun fibers were derived from a random sample of at least 20 fibers.

\section{In vitro Drug Release}

Total immersion method was used to study the cumulative release profiles of $T_{4}$ from drug-loaded fiber mats. A known amount of the fibers $(5 \mathrm{mg})$ was suspended in $10 \mathrm{ml}$ of $\mathrm{pH} 7.4$ phosphate buffer and was placed in a shaking incubator at $37^{\circ} \mathrm{C}$ or $25^{\circ} \mathrm{C}$. Samples of $1 \mathrm{ml}$ were taken from the medium periodically and the released drug was determined using HPLC. The volume of the release medium was kept constant by replacement with same volume of fresh medium. Drug content of the fiber mat was calculated by dissolving a certain amount of mat in the solvent and measuring the total amount of drug by HPLC method. All drug release data were averaged from three measurements.

\section{Preparation of Human Epidermis}

Skin samples of adult Chinese females were obtained with patient consent and ethics approval, after abdominal reduction surgery. This study was approved by the Institutional Review Board (IRB) of Singapore General Hospital, Republic of Singapore (IRB Reference Number 196/2006). This IRB operates in accordance with the International Conference on Harmonization/Singapore Guideline for Good Clinical Practices, and with the applicable regulatory requirements. Subcutaneous fat and dermis were carefully separated from the epidermis after immersing the whole skin in $60 \pm 5^{\circ} \mathrm{C}$ distilled water for $2 \mathrm{~min}$. Samples were stored at $-80^{\circ} \mathrm{C}$ until use. Prior to permeation studies, skin samples with stratum corneum side facing upwards, were equilibrated in $0.9 \% \mathrm{w} / \mathrm{v}$ sodium chloride solutions containing $1 \% \quad \mathrm{v} / \mathrm{v}$ antibacterial antimycotic solution (30).

\section{In vitro Skin Permeation Studies}

Permeation studies of drug-loaded 10\% PNIPAM nanofibers were performed using a flow-through diffusion cell apparatus at $37 \pm 0.5{ }^{\circ} \mathrm{C}$. The donor compartment was filled with $25 \mathrm{mg}$ of fiber mat (by spreading the mat in the donor chamber). A volume of $250 \mu \mathrm{l}$ of water was added to all samples to initiate wetting and drug release from the fiber mat. The control sample was $250 \mu$ of aqueous solution, having an equal amount of drug as the test sample $(n=4)$. The exposed surface area of the skin for the permeation of the drug was $0.785 \mathrm{~cm}^{2}$. Samples from the receptor compartment were collected at predetermined time points over a 24-h period, and the amount of $\mathrm{T} 4$ permeated was analyzed by HPLC. The steady state flux (J) was estimated from the slope of the straight line portion of the cumulative haloperidol absorbed against time profile.

The permeation of drug across the epidermis can be described by Fick's $2^{\text {nd }}$ law of diffusion (31):

$$
Q=A K L C_{o}\left[\frac{D}{L^{2}} t-\frac{1}{6}-\frac{2}{\Pi^{2}} \sum_{n=1}^{\infty} \frac{(-1)^{n}}{n^{2}} e^{-\left(D / L^{2}\right) n^{2} \Pi^{2} t}\right]
$$

Permeation parameters are interpreted from the cumulative amount of released drug per unit skin area $(Q / A)$ versus time $(t)$ plot. The gradient and $x-$ intercept of the linear portion of the plot yield steady-state flux $\left(J_{s s}\right)$ and lag time $\left(t_{L}\right)$ respectively.

The drug permeability $(K D / L)$ is derived as shown in $\mathrm{Eq} 2$ :

$$
\frac{K D}{L}=\frac{J_{s s}}{C_{o}}
$$

where $C_{o}$ is the initial drug concentration in the donor cell. The diffusion parameter, $D / L^{2}$ reflecting the mobility of the drug solute in the skin was calculated using the following equation:

$$
\frac{D}{L^{2}}=\frac{1}{6 t_{L}}
$$

The partition parameter, $K L$, reflecting the distribution of the drug between the skin and the donor solution is derived from:

$$
K L=\frac{K D / L}{D / L^{2}}
$$

All permeation experiments were carried out using skin samples from the same donor. 


\section{Confocal Laser Scanning Microscopy (CLSM)}

Skin penetration of fluorescein loaded $10 \% \mathrm{w} / \mathrm{w}$ PNIPAM- $10 \% \mathrm{w} / \mathrm{w}$ PVA nanofibers were viewed using a CLSM. Control sample was fluorescein dissolved in water. The CLSM was a Nikon A1R laser scanning spectral confocal and digital camera. All samples were excited at $488 \mathrm{~nm}$ and $\mathrm{X}-\mathrm{Z}$ sectioning was used to determine the depth of permeation using an objective of $\times 60$. After 24 -h exposure to fluorescein-loaded PNIPAM-PVA nanofibers, the skin samples were washed three times, placed on a glass slide and covered with a glass cover-slip. The slides were inverted and images were captured through the cover-slip side of the prepared samples. The full epidermis was scanned at different increments through the z-axis of the microscope.

\section{STATISTICS}

Skin permeation of $\mathrm{T}_{4}$ was analyzed using one-way analysis of variance (ANOVA; Graph Pad Prism, Version 2). The differences were considered statistically significant if $\mathrm{p}<0.05$.

\section{RESULTS AND DISCUSSION}

\section{FTIR Measurements of the Drug-loaded Nanofibers}

The interactions between the polymers and $\mathrm{T}_{4}$ were analyzed by FTIR (Fig. 1). For pure PVA (Fig. 1a), a broad band around $3336 \mathrm{~cm}^{-1}$ is attributed to the $\mathrm{O}-\mathrm{H}$ stretching vibration of the hydroxyl group. The vibrational bands at 2942 and $1438 \mathrm{~cm}^{-1}$ represent the $-\mathrm{CH}$ stretching. The sharp peak band at $1095 \mathrm{~cm}^{-1}$ corresponds to $\mathrm{C}-\mathrm{O}$ stretching present in the PVA backbone (Fig. 1a). There was a decline in the intensity of the $-\mathrm{OH}$ band when PVA was mixed with $\mathrm{T}_{4}$ (Fig. 1b). It is clear that hydrogen abstraction occurred from PVA molecule in the presence of $T_{4}$ suggesting the formation of hydrogen bond between PVA and $\mathrm{T}_{4}$ molecules (32-34).

The bands at 2971, 2932 and $2875 \mathrm{~cm}^{-1}$ are associated with the $-\mathrm{CH}$ stretching vibration of PNIPAM fiber in $100 \% \mathrm{v} / \mathrm{v}$ ethanol (Fig. 1f). The positions of these three peaks are sensitive to changes in the conformation of the hydrocarbon chain and they shift towards lower frequencies when placed in aqueous solutions. This could be related to the interaction of the alkyl chain with water causing a decrease in the degree of freedom of the PNIPAM molecules (35-37). FTIR spectra of the polymer blends (Fig. 1c, d) show the presence of both PVA and PNIPAM in the nanofibrous networks. The interactions between the two polymers could be due to hydrogen bonding between hydroxyl group in PVA and amide groups in PNIPAM.

\section{FESEM Analysis of Nanofibers}

Morphological structures of electrospun PVA, PNIPAM and polymer mixtures are shown in Fig. 2. In our study, the electrospinning parameters such as voltage, flow rate and distance between the injector and collector were kept constant, therefore any difference in the morphology or structure of the fibers is related to the intrinsic properties of the polymeric solution. PVA fibers loaded with 1 $\mathrm{mg} / \mathrm{ml}$ of $\mathrm{T}_{4}$ were obtained using drug/polymer solutions at a concentration of $10 \% \mathrm{w} / \mathrm{w}$ polymer in water. Formulation A exhibits uniform fibers with diameter ranging from $\sim 100$ to $200 \mathrm{~nm}$ (Fig. 2a). Continuous fibers of formulation $\mathrm{B}$ without beads or sputtering of the solution were obtained with fiber diameter ranging from 30 to $300 \mathrm{~nm}$. High viscosity and lower surface tension of the ethanolic solution favored the formation of continuous nanofibers as observed with formulation B (38-40). Formulation $\mathrm{C}$ resulted in spindle-like defects therefore it was not used in the other experiments (Fig. 2c). Nevertheless continuous nanofibers were obtained upon electrospinning formulation $\mathrm{D}$ and $\mathrm{E}$, however some elongated and semi-spherical defects were formed along these fibers (Fig. 2d, e).

The mean diameter of the fibers correlated with viscosity of the solution. Fiber diameter increased (from about 100 to $1000 \mathrm{~nm}$ ) when blends of PVA and PNIPAM were used. This could be due to the hydrogel formed when PNIPAM was added into aqueous solutions resulting in higher surface tension values. FESEM detected no levothyroxine crystals on the surface of the fibers, which indicated that levothyroxine was completely embedded in the fibers.

\section{In vitro Drug Release}

The release of $\mathrm{T}_{4}$ from formulation $\mathrm{A}, \mathrm{B}, \mathrm{D}$ and $\mathrm{E}$ were investigated in phosphate buffer solution of pH 7.4 both at body temperature, $37^{\circ} \mathrm{C}$, (Fig. 3) and room temperature, $25^{\circ} \mathrm{C}$ (Fig. 4). 


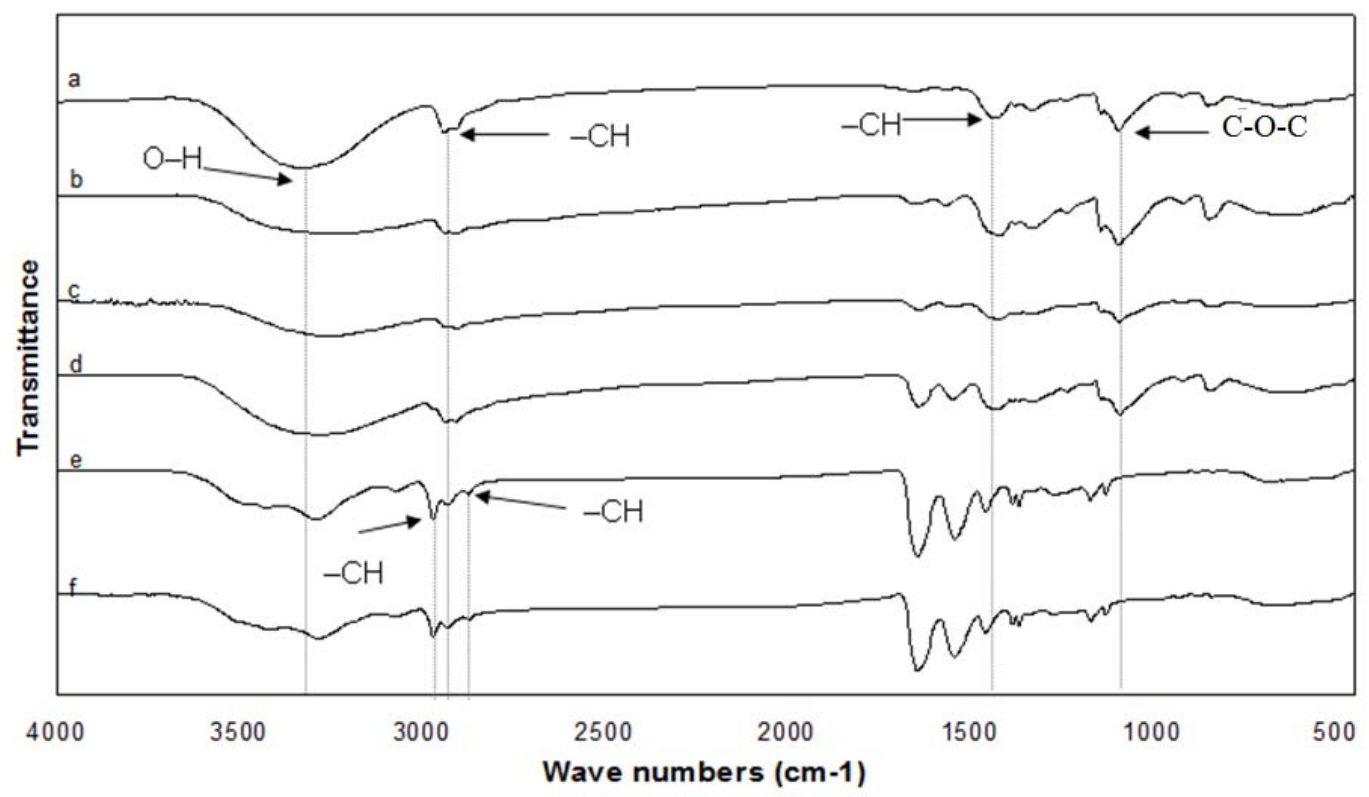

Figure 1. FTIR spectra of formulations (a) A, without the drug (b) A, (c) D, (d) E, (e) B and (f) B without the drug. All formulations contain drug unless otherwise mentioned.

$\mathrm{T}_{4}$ content of the nanofiber mat was calculated, it was found that $25 \mathrm{mg}$ of the polymer fiber mat contained $20 \mu \mathrm{g}$ of the drug. It can be seen that PVA and PNIPAM polymer released around 48\% and $73 \%$ of their total drug content respectively, within the first $15 \mathrm{~min}$ in contact with $\mathrm{PBS}$ in $37^{\circ} \mathrm{C}$, where as the rest of the drug was released gradually over the time period. $\quad \mathrm{T}_{4}$ is speculated to be released from polymer mats by drug diffusion and polymer erosion (degradation) or both mechanisms.

At body temperature of $37^{\circ} \mathrm{C}$, formulation $\mathrm{B}$ released approximately $97 \%$ of its drug content whereas formulation A released only $65 \%$ of its drug content. The release of $\mathrm{T}_{4}$ from mixed polymer mat was found to be a function of PNIPAM concentration used, therefore formulation E released more drug compared to formulation D. This could be explained by the high water solubility of PNIPAM which dissolved almost immediately leading to a rapid release of $\mathrm{T}_{4}$. PVA dissolves in water at temperatures above $90^{\circ} \mathrm{C}$. At body temperature, electrospun fibers of PVA have a disintegration time of a few weeks (7). Drug release rates from formulations containing PVA were lower due to the slow degradation of PVA nanofibers compared to PNIPAM nanofibers. Thus, PNIPAM and PVA blends could prolong drug release with less risk of toxicity compared to pure PNIPAM fibers. The drug release at $25^{\circ} \mathrm{C}$ from formulation $\mathrm{B}$ was relatively lower than at $37^{\circ} \mathrm{C}$ (>LCST). Considering that PNIPAM is a thermosensitive polymer, it can be used for regulating drug release via response to temperature change. At temperatures below LCST, the polymer is stable and the drug release is slower, however at higher temperatures the polymer collapses thereby enhancing drug release (41).

\section{In vitro Skin Permeation}

Fig. 5 represents cumulative $\mathrm{T}_{4}$ from formulation $\mathrm{A}$, $\mathrm{B}, \mathrm{E}$ and control as a function of time. It can be seen that $\mathrm{T}_{4}$ permeation across the skin was gradual ( $>0.05)$ and there is evidence of drug accumulation in the skin as shown by the low amounts of drug permeation across the skin (Fig. 5) and the high amounts of $\mathrm{T}_{4}$ deposition detected on the skin surface (results not shown). Skin retention of $T_{4}$ was improved when polymeric carriers were used. $\mathrm{T}_{4}$ skin retention from formulation A was markedly higher than that of formulation $\mathrm{B}$, probably due to the low degradation rate of PVA nanofibers. Blending PVA and PNIPAM (formulation E) managed to increase the skin retention of $\mathrm{T}_{4}$ when compared to pure PNIPAM nanofiber mat containing $\mathrm{T}_{4}$. Table 2 summarizes skin permeation parameters of $\mathrm{T} 4$ from different nanofiber formulations across the skin. 


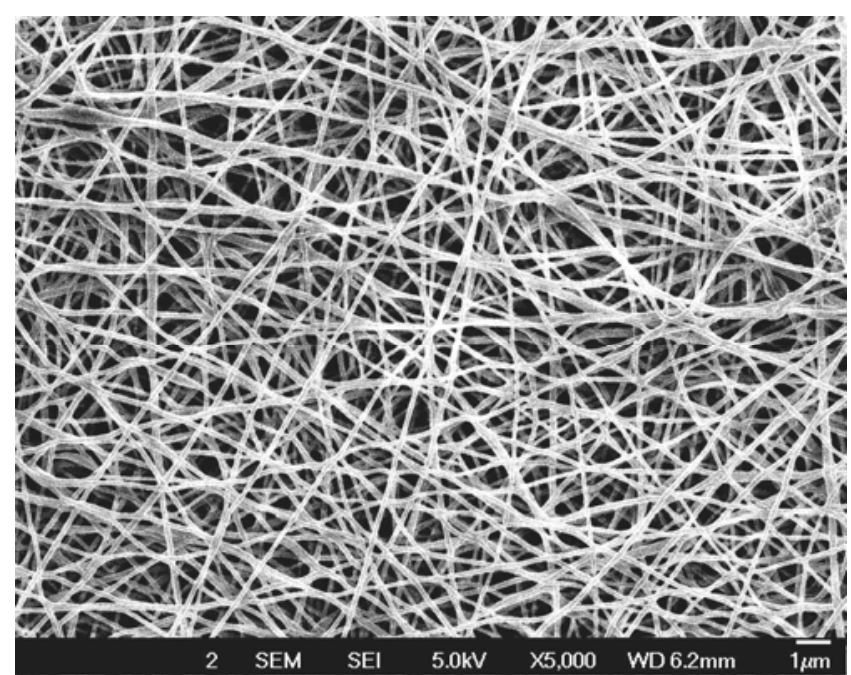

(a)

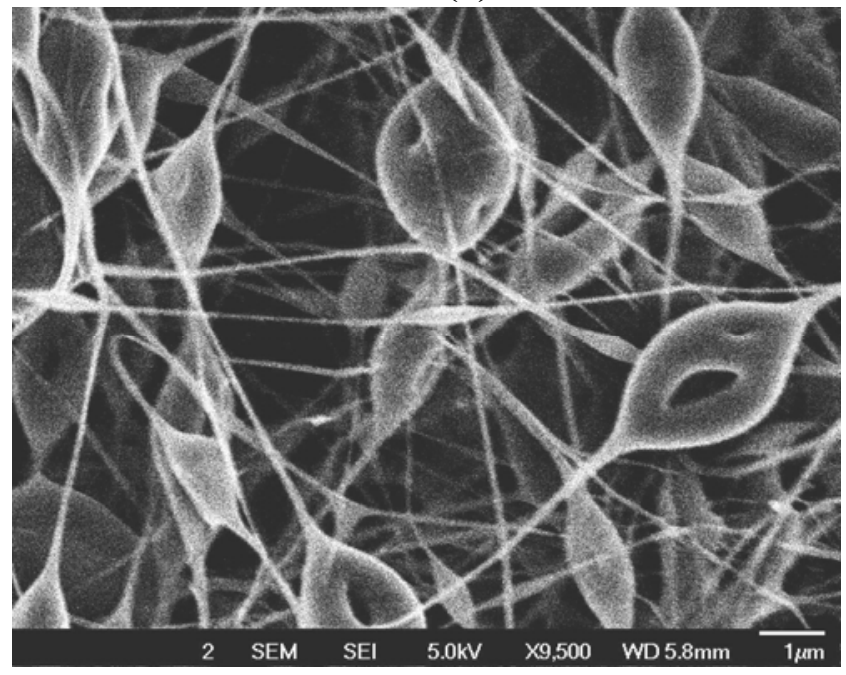

(c)

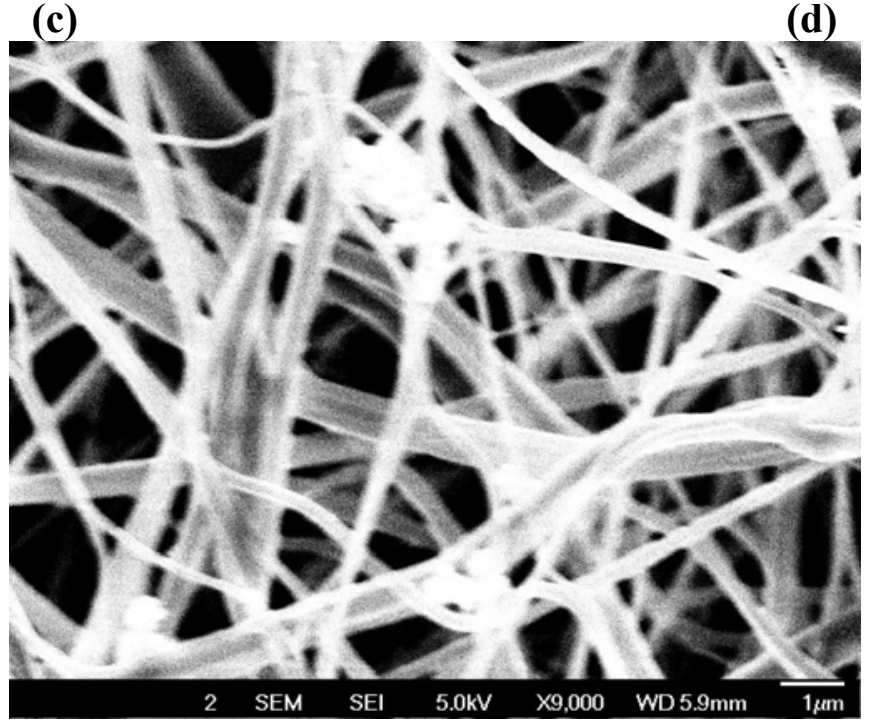

(e)

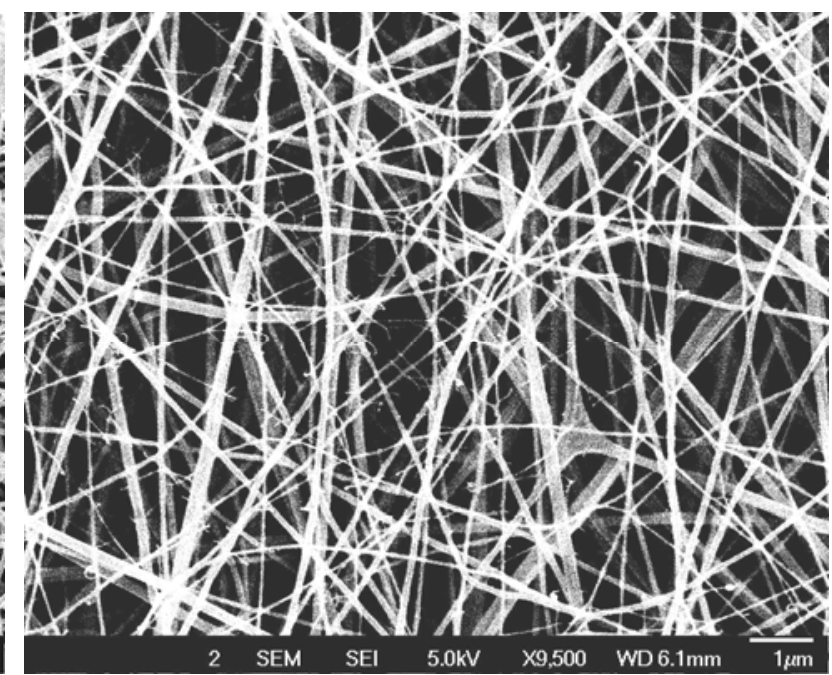

(b)

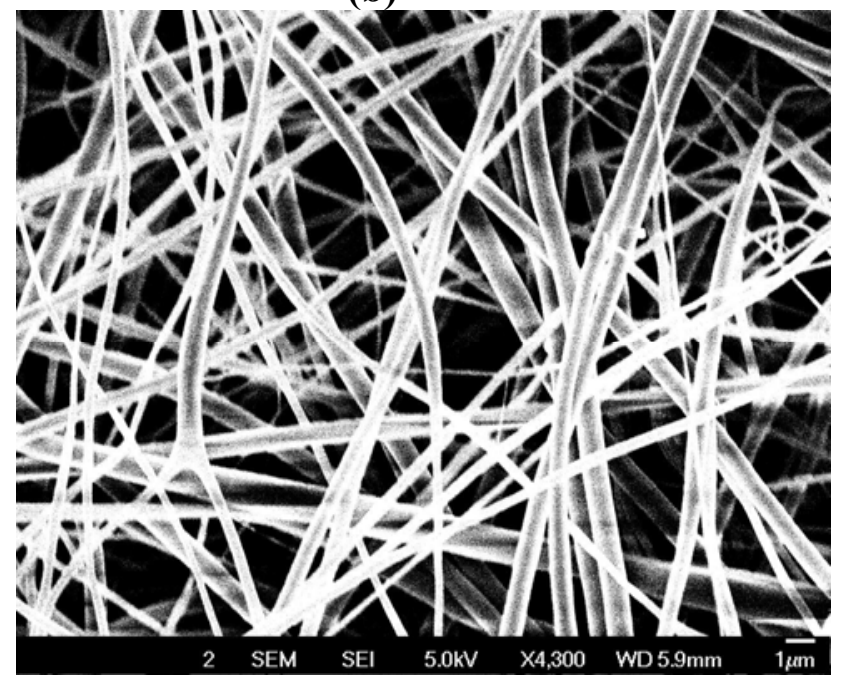

(d) 


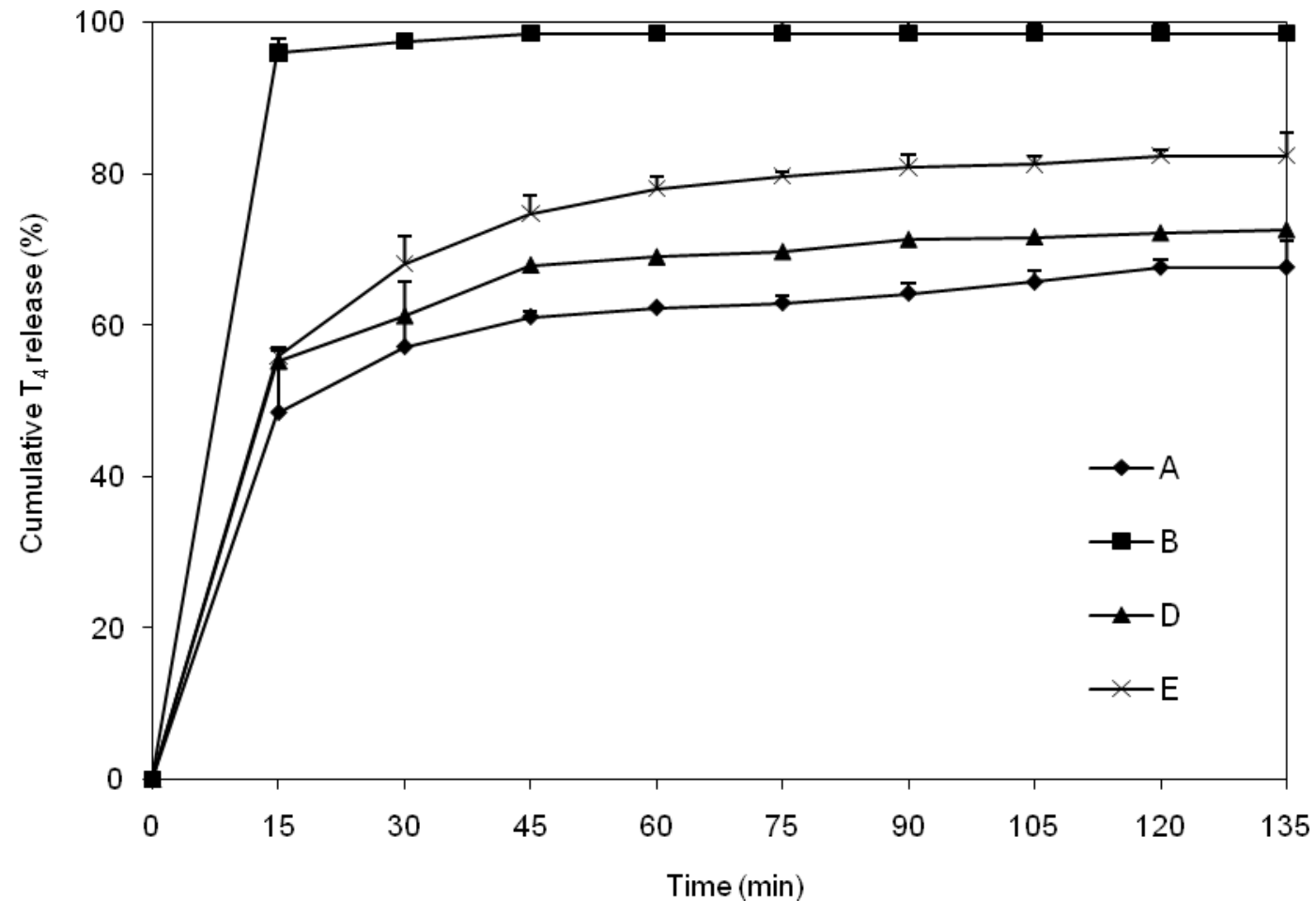

Figure 3. In vitro release profile of $\mathrm{T}_{4}$ from electrospun mat in phosphate buffer $(\mathrm{pH} 7.4)$ at body temperature $\left(37^{\circ} \mathrm{C}\right)$.

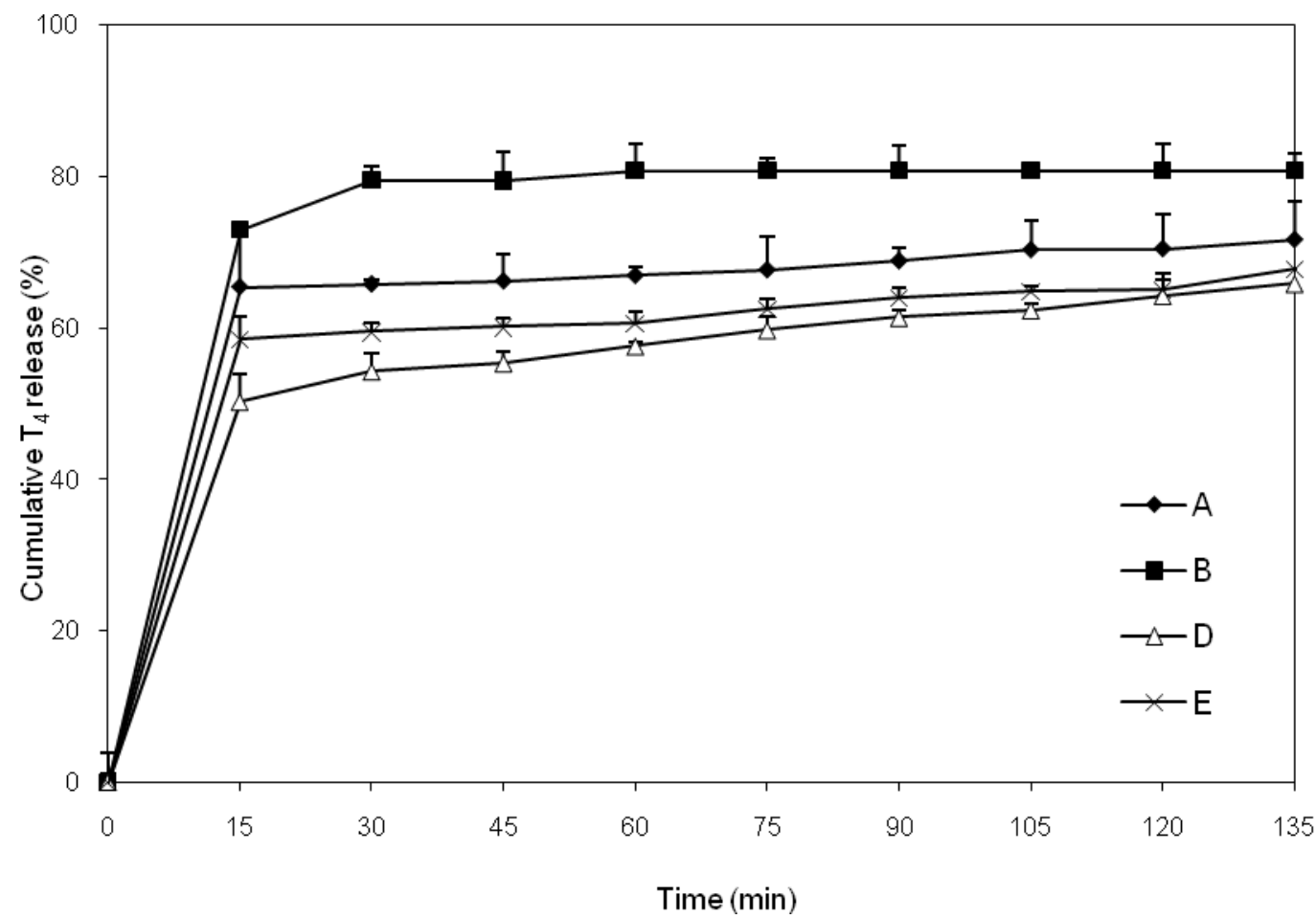

Figure 4. In vitro release profile of $\mathrm{T}_{4}$ from electrospun mat in phosphate buffer $\left(\mathrm{pH} \mathrm{7.4)}\right.$ at room temperature $\left(25^{\circ} \mathrm{C}\right)$. 


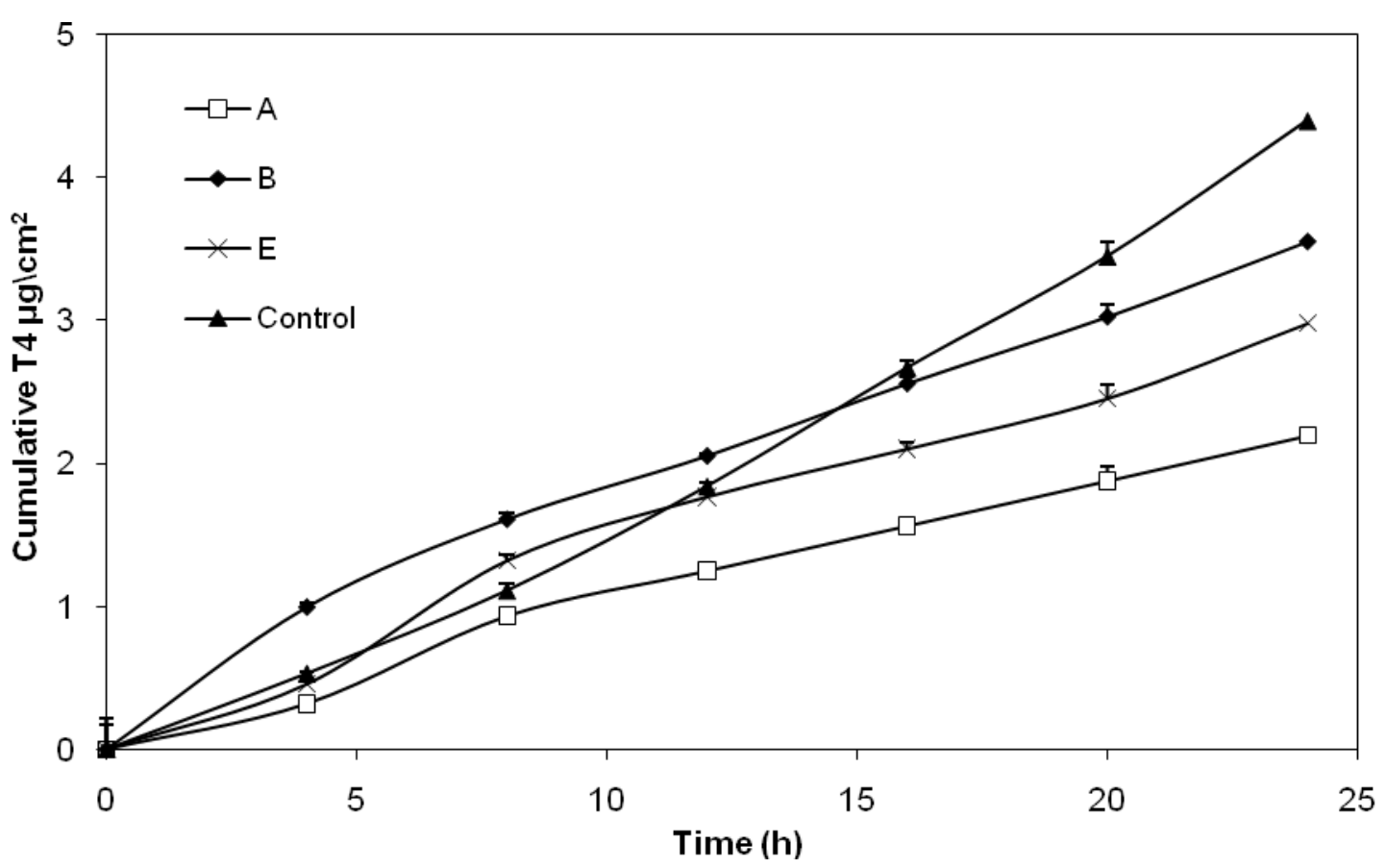

Figure 5. $\mathrm{T}_{4}$ permeation across human epidermis $(\mathrm{n}=4)$.

\begin{tabular}{lllll}
\hline \multicolumn{6}{l}{ Table 2. } & Permeation profile of different nanofiber formulation $(\mathrm{n}=4)$. & \\
\hline Formulation & Mean flux $\pm \mathbf{S D}\left(\boldsymbol{\mu g} / \mathbf{c m}^{2} / \mathbf{h}\right)$ & Lag time $(\mathbf{h})$ & Drug permeability $(\mathbf{c m} / \mathbf{h})$ & Diffusion parameter $\left(\mathbf{h}^{-1}\right)$ \\
\hline $\mathrm{A}$ & $0.314 \pm 0.045^{* * *}$ & $2.978 \pm 0.691^{*}$ & $6.335 \pm 0.376^{* * *}$ & $0.496 \pm 0.213^{*}$ \\
$\mathrm{~B}$ & $0.598 \pm 0.025^{* *}$ & $2.372 \pm 0.145$ & $5.047 \pm 0.240^{* * *}$ & $0.395 \pm 0.015$ \\
$\mathrm{E}$ & $0.399 \pm 0.031^{* * *}$ & $3.333 \pm 1.114^{*}$ & $7.092 \pm 0.325^{* * *}$ & $0.556 \pm 0.027^{*}$ \\
Control & $0.846 \pm 0.073$ & $1.152 \pm 0.205$ & $2.451 \pm 0.157$ & $0.192 \pm 0.011$ \\
\hline
\end{tabular}

* Statistically significant at $\mathrm{P}<0.05$

** Statistically significant at $\mathrm{P}<0.01$

$* * *$ Statistically significant at $\mathrm{P}<0.001$

It can be seen that flux rate of the control samples $\left(\mathrm{J}=0.846 \pm 0.073 \mu \mathrm{g} / \mathrm{cm}^{2} / \mathrm{h}\right)$ is higher than the nanofiber mat formulations $(p<0.05)$. Nanofibers containing pure PVA had lower flux when compared to samples containing pure PNIPAM or a mixture of the two polymers. This shows that a combination of PVA and PNIPAM polymers effectively retarded the flux rate of $\mathrm{T}_{4}$, and PVA polymer alone was the most effective in retarding the flux rate.

The recommended therapeutic dose of $\mathrm{T}_{4}$ is 50 $100 \mu \mathrm{g} /$ day. Therefore the cumulative $\mathrm{T}_{4}$ skin penetration obtained in this study would not be sufficient to produce a systemic effect in vivo.
Topical efficacy was improved as the drug accumulation on the skin prolonged release (29).

To support the above hypothesis CLS microscopic studies were conducted. Skin samples were treated with formulation E loaded with fluorescein and the control samples were treated with an aqueous solution containing same concentration of fluorescein. The binary images (Fig. 6b) indicate the localization of green fluorescein on the outer layer of the skin samples treated with this formulation as compared with the control. It can be seen that the flourescein dye could not penetrate the skin samples treated with formulation $\mathrm{E}$ and the dye concentrated at the outer layer of the skin. 
a) PNIPAM-PVA nanofiber mat
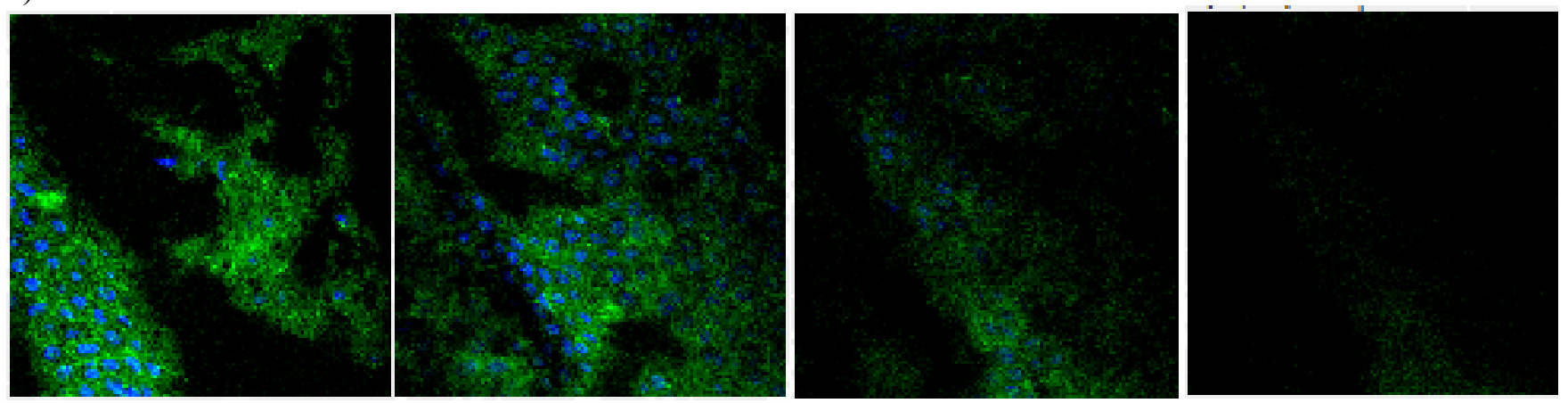

Control
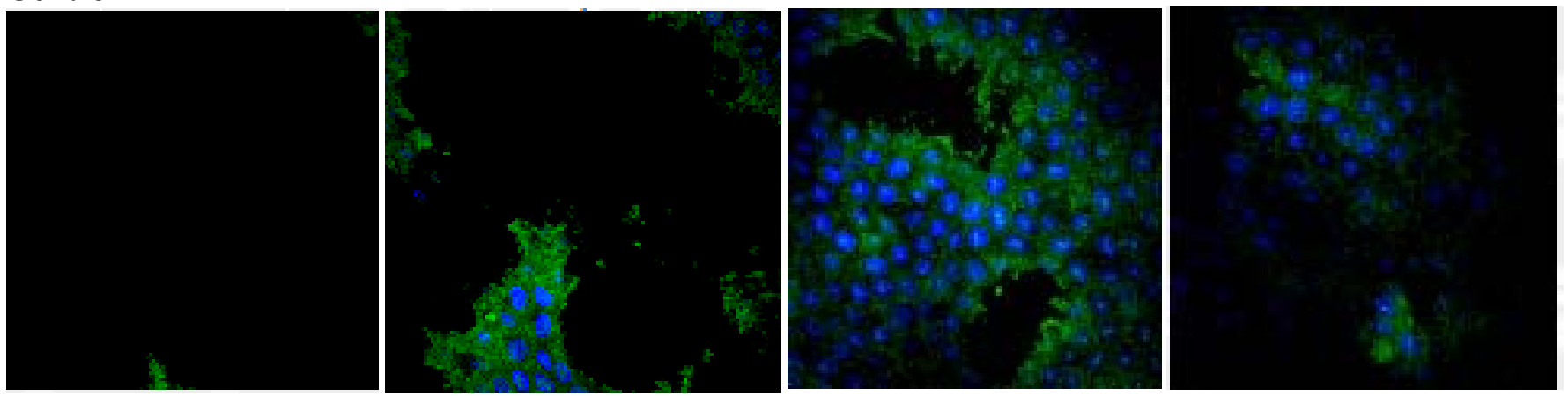

b) PNIPAM-PVA nanofiber mat
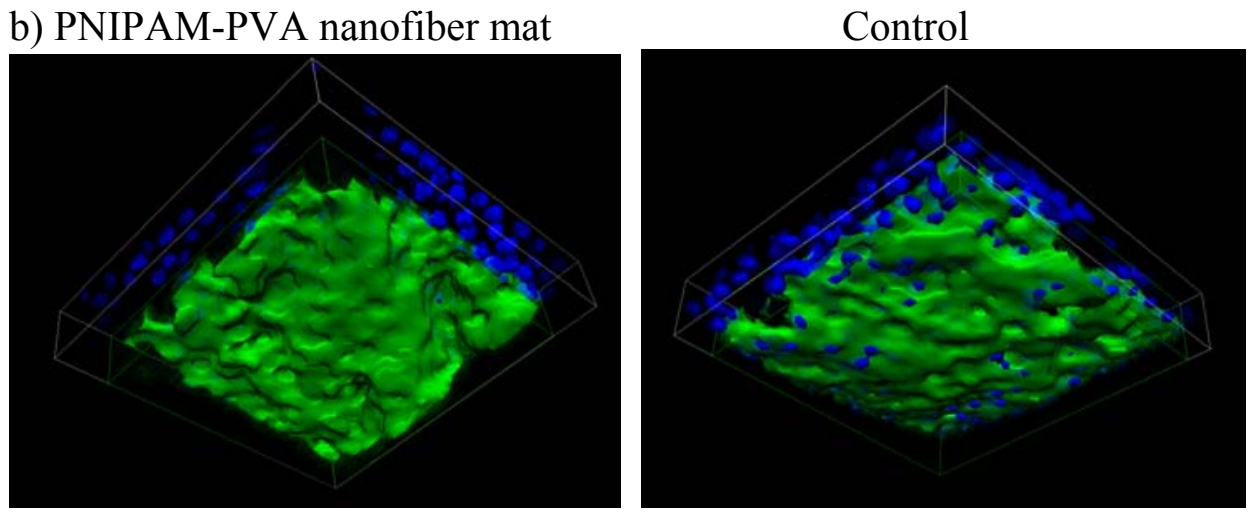

Figure 6 Image of the epidermis and localization of green fluorescence incorporated in to formulation $\mathrm{E}$ as a function of depth into the skin. The image depths (from left to right) are $0,8,16$ and $24 \mu \mathrm{m}$. b) Binary image of the skin after the flow through diffusion studies. Staining of cell nuclei with DAPI is shown as blue signal.

This may be due to the impermeable barrier of the polymer above its LCST temperature which prevents the penetration of the flourescein. However, fluorescein was detected in the lower layers of the epidermis treated with aqueous solution that did not contain any polymer. For better visualization, skin cell nuclei were counterstained with DAPI.
These polymeric nanofiber delivery systems may have potential use in skin formulations containing active ingredients that are meant to be concentrated on the skin surface and can help to increase the retention of the drug on the skin layers. Due to the lower dosing frequency and simpler dosage regimes, patient compliance may also be improved. 


\section{CONCLUSION}

Effective sustained delivery of $\mathrm{T}_{4}$ has been achieved by using polymeric nanofibers which could relatively improve therapy by reducing number of applications. These nanofiber mats may be promising carriers for sustained topical delivery of drugs while keeping the drugs concentrated on the skin over a prolonged period with reduced systemic uptake.

\section{ACKNOWLEDGMENT}

The authors would like to thanks Dr Clement Khaw from Singapore Bioimaging Consortium (SBIC) for his guidance and assistance in using the confocal laser microscopy.

\section{REFERENCES}

1. Chen JP. Chang GY. Chen JK. Electrospun collagen/chitosan nanofibrous membrane as wound dressing. Colloids Surf A Physicochem Eng Asp, 313: 183-188, 2007.

2. Matsumoto H. Yako H. Minagawa M. Tanioka A. Characterization of chitosan nanofiber fabric by electrospray deposition: Electrokinetic and adsorption behavior. J Colloid Interface Sci, 310: 678-681, 2007.

3. Frenot A. Chronakis IS. Polymer nanofibers assembled by electrospinning. Curr Opin Colloid Interface Sci, 8: 64-75, 2003.

4. Yang D. Li Y. Nie J. Preparation of gelatin/PVA nanofibers and their potential application in controlled release of drugs. Carbohydr Polym, 69: 538-543, 2007.

5. Jia YT. Gong J. Gu XH. Kim HY. Dong J. Shen XY. Fabrication and characterization of poly (vinyl alcohol)/chitosan blend nanofibers produced by electrospinning method. Carbohydr Polym, 67: 403409, 2007.

6. Huang ZM. Zhang YZ. Ramakrishna S. Lim CT. Electrospinning and mechanical characterization of gelatin nanofibers. Polymer, 45: 5361-5368, 2004.

7. Kenawy ER. Abdel-Hay FI. El-Newehy MH. Wnek GE. Controlled release of ketoprofen from electrospun poly (vinyl alcohol) nanofibers. Mater Sci Eng A, 459: 390-396, 2007.

8. Tao J. Shivkumar S. Molecular weight dependent structural regimes during the electrospinning of PVA. Materials Lett, 61: 2325-2328, 2007.

9. Li L. Hsieh YL. Chitosan bicomponent nanofibers and nanoporous fibers. Carbohydr Res, 341: 374381, 2006.
10. Mincheva R. Manolova N. Rashkov I. Biocomponent aligned nanofibers of $\mathrm{N}$ carboxyethylchitosan and poly (vinyl alcohol). Eur Polym J, 43: 2809-2818, 2007.

11. Liang D. Hsiao BS. Chu B. Functional electrospun nanofibrous scaffolds for biomedical applications. Adv Drug Deliv Rev, 59; 1392-412, 2007.

12. Ogata T. Nonaka T. Kurihara S. Permeation of solutes with different molecular size and hydrophobicity through the poly (vinyl alcohol)graft-N-isopropylacrylamide copolymer membrane. J Memb Sci, 103: 159-165, 1995.

13. Ruel-Gariépy E. Leroux JC. In situ-forming hydrogels-review of temperature-sensitive systems. Eur J Pharm Biopharm, 58: 409-426, 2004.

14. Wei H. Zhang X. Cheng C. Cheng SX. Zhuo RX. Self-assembled, thermosensitive micelles of a star block copolymer based on PMMA and PNIPAAm for controlled drug delivery. Biomaterials, 28: 99107, 2007.

15. Shin Y. Chang JH. Liu J. Williford R. Shin YK. Exarhos GJ. Hybrid nanogels for sustainable positive thermosensitive drug release. J Control Release, 73: 1-6, 2001.

16. Zhang XZ. Wu DQ. Chu CC. Synthesis, characterization and controlled drug release of thermosensitive IPN-PNIPAAm hydrogels. Biomaterials, 25: 3793-3805, 2004.

17. Don TM. Huang ML. Chiu AC. Kuo KH. Chiu WY. Chiu LH. Preparation of thermo-responsive acrylic hydrogels useful for the application in transdermal drug delivery systems. Materials Chem Phys, 107: 266-273, 2008.

18. Han HD. Shin BC. Choi HS. Doxorubicinencapsulated thermosensitive liposomes modified with poly ( $\mathrm{N}$-isopropylacrylamide-co-acrylamide): Drug release behavior and stability in the presence of serum. Eur J Pharm Biopharm, 62: 110-116, 2006.

19. Wang YJ. Winnik FM. Clarke RJ. Interaction between DMPC liposomes and HM-PNIPAM polymer. Biophys Chem, 104: 449-458, 2003.

20. Kim JC. Kim JD. Release property of temperaturesensitive liposome containing poly $(\mathrm{N}-$ isopropylacrylamide). Colloids Surf B Biointerfaces, 24: 45-52, 2002.

21. Kono K. Henmi A. Yamashita H. Hayashi H. Takagishi T. Improvement of temperaturesensitivity of poly ( $\mathrm{N}$-isopropylacrylamide)modified liposomes. J Control Release, 59: 63-75, 1999.

22. Malonne H. Eeckman F. Fontaine D. Otto A. De Vos L. Moës A. Fontaine J. Amighi K. Preparation of $\operatorname{poly}(N$-isopropylacrylamide) copolymers and preliminary assessment of their acute and subacute toxicity in mice. Eur J Pharm Biopharm, 61: 188-194, 2005. 
23. Patel H. Stalcup A. Dansereau R. Sakr A. The effect of excipients on the stability of levothyroxine sodium pentahydrate tablets. Int J Pharm, 264: 3543, 2003.

24. Volpato NM. Silva RL. Brito APP. Gonçalves JCS. Vaisman M. Noël F. Multiple level C in vitro/in vivo correlation of dissolution profiles of two 1thyroxine tablets with pharmacokinetics data obtained from patients treated for hypothyroidism. Eur J Pharm Sci, 21: 655-660, 2004.

25. Arduino C. Eandi M. Kinetics of thyroxine epicutaneous absorption. Pharmacol. Res, 21: 109110, 1989.

26. Santini F. Vitti P. Chiovato L. Ceccarini G. Macchia M. Montanelli L. Gatti G. Rosellini V. Mammoli C. Martino E. Chopra IJ. Safer JD. Braverman LE. Pinchera A. Role for inner ring deiodination preventing transcutaneous passage of thyroxine. J Clin Endocrinol Metab, 88: 2825-2830, 2003.

27. Pucci E. Chiovato L. Pinchera A. Thyroid and lipid metabolism. Int J Obes Relat Metab Disord, 24: S109-S112, 2000.

28. James M. Wepierre J. Percutaneous absorption in vivo of iodine-125- labeled thyroxine and iodine125-labeled triiodothyronine in the rat. Ann Pharm Francaises, 32: 633-640, 1974.

29. Padula C. Pappani A. Santi P. In vitro permeation of levothyroxine across the skin. Int J Pharm, 349: 161$165,2008$.

30. Kligman AM. Christophers E. Preparation of isolated sheets of human stratum corneum. Arch Dermatol, 88: 702-705, 1963.

31. Crank J, The mathematics of diffusion, Oxford University Press, England, 47-53, 1975.

32. Şanlı O. Ay N. Işıklan N. Release characteristics of diclofenac sodium from poly (vinyl alcohol)/sodium alginate and poly (vinyl alcohol)-grafted-poly (acrylamide)/sodium alginate blend beads. Eur J Pharm Biopharm, 65: 204-214, 2007.

33. Hong J. Hong CK. Shim SE. Synthesis of polystyrene microspheres by dispersion polymerization using poly (vinyl alcohol) as a steric stabilizer in aqueous alcohol media. Colloids Surf A Physicochem Eng Asp, 302: 225-233, 2007.
34. Arndt KF. Richter A. Ludwig S. Zimmermann J. Kressler J. Kuckling D. Adler HJ. Poly (vinyl alcohol)/poly (acrylic acid) hydrogels: FTIR spectroscopic characterization of crosslinking reaction and work at transition point. Acta Polymerica, 50: 383-390, 1999.

35. Liu M. Bian F. Sheng F. FTIR study on molecular structure of poly ( $\mathrm{N}$-isopropylacrylamide) in mixed solvent of methanol and water. Eur Polymer J, 41: 283-291, 2005.

36. Maeda Y. Nakamura T. Ikeda I. Changes in the hydration states of poly (N-Npropylmethacrylamide) and poly (Nisopropylmethacrylamide) during their phase transitions in water observed by FTIR spectroscopy. Macromolecules, 34: 8246-8251, 2001a.

37. Maeda Y. Nakamura T. Ikeda I. Changes in the hydration state of poly (N- alkylacrylamide) during their phase transition in water observed by FTIR spectroscopy. Macromolecules, 34: 1391-1399, $2001 b$.

38. Fong H. Chun I. Reneker DH. Beaded nanofibers formed during electrospinning. Polymer, 40: 45854592, 1999.

39. Xu X. Chen X. Liu A. Hong Z. Jing X. Electrospun poly (L-lactide)-grafted hydroxyapatite/poly (Llactide) nanocomposite fibers. Eur Polym J, 43: 3187-3196, 2007.

40. Verreck G. Chun I. Rosenblatt J. Peeters J. Dijck AV. Mensch J. Noppe M., Brewster ME. Incorporation of drugs in an amorphous state into electrospun nanofibers composed of a waterinsoluble, non-biodegradable polymer. J Control Release, 92; 349-360, 2003.

41. Kato N. Oishi A. Takahashi F. Peptide synthesis catalyzed by $\alpha$-chymotrypsin immobilized in the poly (N-isopropylacrylamide/acrylamide) gel. Mater Sci Eng, 13: 109-116, 2000. 